\title{
Comparative investigation into the effect of fertigation and of broadcast fertilization on the yield and nitrate content of lettuce (Lactuca sativa L.)
}

M. J. Bakker (soil science student), J. H. G. Slangen (Department of Soil Science and Plant Nutrition, Agricultural University, Wageningen, Netherlands) and W. Glas (UKF, Maliebaan 81, 3581 CG Utrecht, Netherlands)

Received 29 November 1984; accepted 17 December 1984

\begin{abstract}
The effects of method of application of nitrogen on yield and nitrate content of lettuce (Lactuca sativa $\mathrm{L}$.) were investigated. Plants grown by applying $\mathrm{N}$ through the irrigation system (fertigation) were compared with plants fertilized with broadcast nitrogen.

For the statistical analysis of the results the data were fitted into a 2 nd-degree polynomial model. Fertigation proved to increase the availability and uptake of $\mathrm{N}$, hence increasing the nitrate content of the crop compared to broadcast fertilization. Yield however was much less effected by method of fertilization.

Key-words: lettuce, Lactuca sativa L., fertigation, broadcast fertilization, yield, nitrate content, 2 nd-degree polynomial model.

Introduction. High levels of nitrate in vegetables may have harmful effects on human health (Corré \& Breimer, 1979). That is why the Dutch Government recently introduced standards for the admissible nitrate content of a number of vegetables (Breimer, 1982). One way of achieving lower nitrate is by optimizing the amount and timing of $\mathrm{N}$ fertilization. Lettuce grown in the Netherlands usually is fertilized by broadcast application of the total amount of estimated $\mathrm{N}$ need before planting. This could lead to luxury consumption of $\mathrm{N}$, resulting in relatively high levels of nitrate in the crop. Applying $\mathrm{N}$ through the irrigation system during cultivation offers a means for a better adjustment of $\mathrm{N}$ fertilization to the nutritional need of the crop, thus limiting luxury consumption and nitrate content (Corré \& Breimer, 1979; Breimer, 1982).
\end{abstract}

Material and methods. During spring and summer of 1983 successively three different cultivars of lettuce (Lactuca sativa L.) were grown on a sandy soil. For each of these experiments the treatments were: no $\mathrm{N}$ application (control) and fertilization with different amounts of ammonium nitrate either in split applications through the raining system or in single application, broadcast before planting. All experimental units received the same water supply.

After harvesting the yield was determined and dried plant material was analysed as described by Novozamsky et al. (1983); amongst others, $\mathrm{NO}_{3}$ and $\mathrm{N}_{\text {total }}$ content 330 
were measured. The effect of method of $\mathrm{N}$ application was statistically analysed by fitting the data into a 2nd-degree polynomial with the general equation $\mathrm{E}(y)=a+$ $b_{1} x_{1}+b_{2} x_{11}+b_{3} x_{2}+b_{4} x_{22}$. The terms $\mathrm{b}_{1}$ and $\mathrm{b}_{3}$, and $\mathrm{b}_{2}$ and $\mathrm{b}_{4}$, respectively represent the regression coefficients of the linear, and quadratic component of the curves describing either the effect of broadcast fertilization $\left(b_{1} x_{1}+b_{2} x_{11}\right)$ or of fertigation $\left(b_{3} x_{2}+b_{4} x_{22}\right)$. Differences resulting from the method of application should find expression in differences between the two curves. This was analysed by introducing a $\delta$, changing the equation into $\mathrm{E}(y)=a+b_{1} \delta x_{1}+b_{2} \delta^{2} x_{11}+b_{3} x_{2}+b_{4} x_{22}$. By feeding of several arbitrary values of delta into this equation the curve corresponding with the data of broadcast fertilization could be shifted to obtain the best possible fit of the two curves. Values of $\delta \neq 1.00$ resulting in the best fit indicate the existence of significant differences between the two curves or, in other words, method of application resulted in a significantly different response by the crop.

Results. In the first cropping, yield was significantly higher when $\mathrm{N}$ was applied by fertigation, compared with broadcast application. In the following croppings, however, no significant differences in yield resulting from method of fertilization (Table I) were found. Although, because of a lack of fit of data into the 2nd-degree polynomial model, some of the findings are less reliable, the results concerning $\mathrm{NO}_{3}$ and $\mathrm{N}_{\text {total }}$ content clearly indicate that application of $\mathrm{N}$ through the raining system leads to a comparatively high level of $\mathrm{N}$ in the crop (Table 1). This is also expressed in a relatively high $\mathrm{N}$ recovery percentage by the fertigated crop, especially at lower $\mathrm{N}$ fertilization levels. The portion of $\mathrm{NO}_{3}-\mathrm{N}$ in the $\mathrm{N}_{\text {total }}$ content is higher in fertigated crop, compared with broadcast fertilization.

Soil analyses at the end of the growth periods showed consistently higher levels of soil $\mathrm{N}\left(\mathrm{NO}_{3}-\mathrm{N}+\mathrm{NH}_{4}-\mathrm{N}\right)$ for the fertigated crop than for the crop fertilized with comparable amounts of broadcast $\mathrm{N}$.

Discussion. The significant differences in yield resulting from the method of $\mathrm{N}$ application in Experiment 1 may be related to the extremely wet conditions under which this experiment took place (a rain surplus of $56 \mathrm{~mm}$ in contrast with a rain deficit of $105 \mathrm{~mm}$ and $116 \mathrm{~mm}$ during Experiments 2 and 3). Under these circumstances leaching of $\mathrm{NO}_{3}$ from the upper soil layer is to be expected. A regular resupply of $\mathrm{N}$ by means of fertigation may have, at least partly, compensated for these losses, resulting in relatively higher yields.

In general however fertigation hardly seems to effect yield, compared with broadcast application of $\mathrm{N}$.

On the other hand fertigation seems to increase the overall availability of soil $\mathrm{N}$, resulting in an increased uptake of $\mathrm{N}$, part of which is luxury consumption. Nevertheless, the highest levels of $\mathrm{NO}_{3}$ in the crop obtained in these experiments were still well below the limit of $4000 \mathrm{mg} / \mathrm{kg}$ fresh weight laid down by the Dutch Government. This leads to the conclusion that fertigation, with a technique as used in these experiments, does not offer a means to lower the nitrate content in lettuce. A lower crop $\mathrm{NO}_{3}$ content may be obtained by adjusting the fertilization regime, i.e. a total stop of $\mathrm{N}$ fertilization a few weeeks before harvesting could be considered. 
M. J. BAKKER, J. H. G. SLANGEN AND W. GLAS

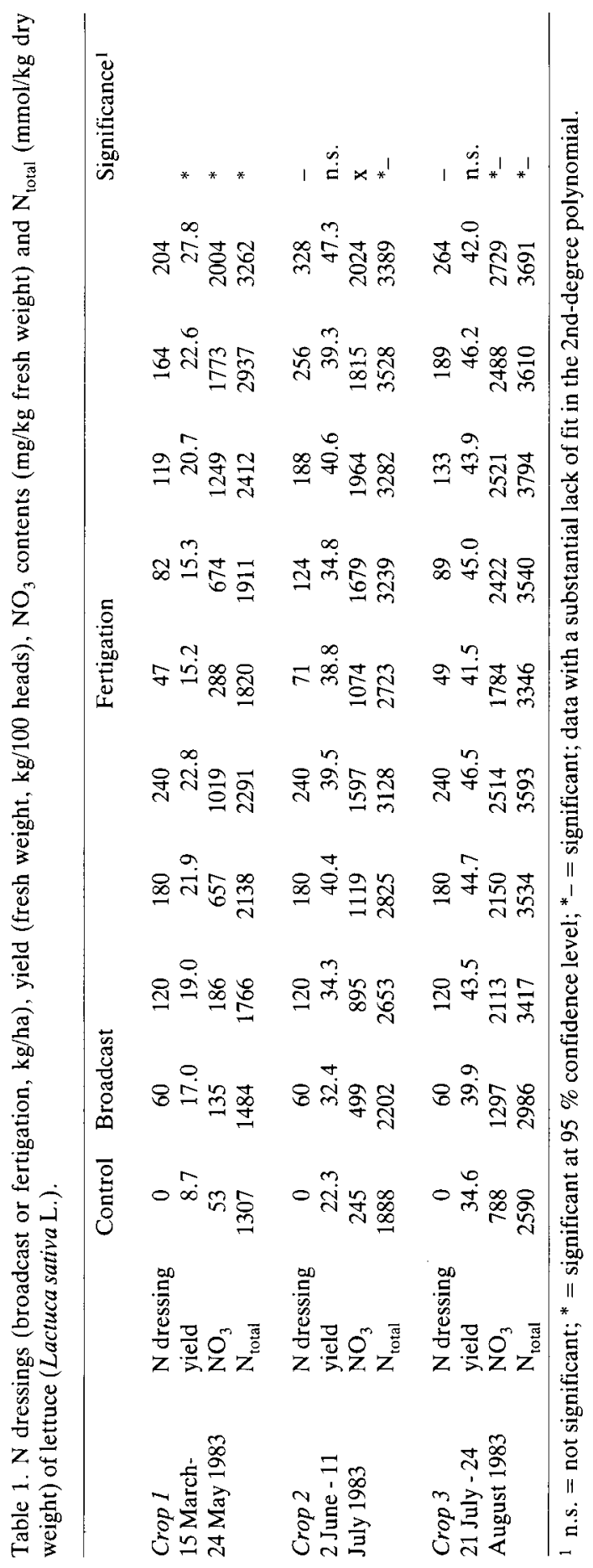


Acknowledgements. Thanks are due to UKF (Unie van Kunstmestfabrieken Utrecht, Netherlands) for their technical and financial assistance, as well as to R. Kramer and co-workers of the Experimental Station 'Noord-Brabant' at Breda for their part of the cultivation of the lettuce crops.

The discussions with Dr Ir M. A. J. van Montfort and Ir P. H. van Ewijk and their assistance were highly appreciated.

Mr P. Squire (UKF) corrected the English text.

\section{References}

Breimer, T., 1982. Environmental factors and cultural measures effecting the nitrate in spinach. Fertilizer Research, 3(3): 191-292.

Corré, W. J. \& T. Breimer. 1979. Nitrate and nitrite in vegetables. Literature Survey 39, Pudoc, Wageningen.

Novozamsky, I., V. J. G. Houba, R. van Eck \& W. van Vark, 1983. A novel digestion technique for multi-element plant analyses. Communication in Soil Science and Plant Analysis 14(3): 239-248.

This synopsis is based on a student thesis entitled 'Vergelijkend onderzoek naar het effekt van fertigatie en breedwerpige bemesting op o.a. de opbrengst en het nitraatgehalte van kropsla (Lactuca sativa L.)', State University, Groningen, Netherlands, 1984. iv + 96 pp. +42 pp. of appendices, 15 figs., 18 tables, 121 refs. Dutch.

Available as paper copy (order R025P, $f 30$ including postage) or microfiches (order R025M, $f$ 17,50 including postage) at: NARD, clo Pudoc, P.O. Box 4, 6700 AA Wageningen, Netherlands (telex 45015 blhwg $n l$ ).

\section{Book review}

M. Menenti, Physical aspects and determination of evaporation in deserts. Institute for Land and Water Mangement Research (ICW), Wageningen, Netherlands, 1984.

Life in semi-arid and arid regions is often dependent upon wells for drinking water, industry and crops. Use is made, increasingly, of irrigation to raise crops in many parts of the world, including the Middle East and northern Africa. Particularly for irrigation are large quantities of water required. It is often obtained from aquifers: water-containing layers in the subsoil that were filled in times with much precipitation. The determination of the size of aquifers, and of their current rate of recharge and of discharge, has therefore attracted attention of development agencies and scientists. The West Lybian Aquifer System in Lybia and neighbouring countries extends over some $800000 \mathrm{~km}^{2}$. Most of it is hundreds of meters below the surface, but in depressions the water-table is less than a few metres deep. Oases are small depressions where the water-table is higher than the soil surface. These areas with easily accessible water have been known for ages. Evaporation has there continued to be in excess of the precipitation, which is only some dozens of millimetres per 